\title{
CARTILHAS PARA O IDOSO? UMA ANÁLISE DESTE INSTRUMENTO PARA O TRATAMENTO DE POLÍTICAS PÚBLICAS
}

\author{
Patrícia Marins Farias ${ }^{1}$
}

Any Brito Leal Ivo ${ }^{2}$

\author{
Bianca Ariele Góes Soares ${ }^{3}$
}

Laércio Souza dos Santos ${ }^{4}$

\begin{abstract}
RESUMO
A questão do processo de envelhecimento do Brasil vem ganhando destaque na literatura recente. Estas novas demandas sugerem a análise e discussão de instrumentos voltados para o incentivo da autonomia e independência do idoso. $O$ presente trabalho visa diagnosticar o acesso do idoso às informações necessárias para o exercício dos seus direitos previstos nas políticas públicas. Inicialmente, foi elaborada uma pesquisa documental a fim de investigar o nível de informação relacionada às políticas públicas voltadas para o idoso por meio de cartilhas. A partir de uma metodologia sistemática foi possível analisar a quantidade e qualidade das cartilhas disponibilizadas para os idosos no Brasil, no âmbito das instituições públicas. Os resultados apresentados confirmaram algumas observações iniciais dos pesquisadores. As cartilhas possuem diferentes formas de apresentação e linguagem que devem ser tratadas com critérios adequados. Os conteúdos trabalhados em cartilhas voltadas para o idoso abrangem o Estatuto do Idoso e demandas locais com linguagens e formatos, muitas vezes, inadequados ao que se propõe. Outro ponto observado foi a carência de orientações relacionadas ao espaço de morar. A partir das observações e percepções das cartilhas pesquisadas foi possível perceber que estes instrumentos ainda podem ser trabalhados de forma eficiente e significativa para a vida do idoso.
\end{abstract}

PALAVRAS-CHAVE: idoso; políticas públicas; cartilha

\section{BOOKLETS FOR THE ELDERLY? AN ANALYSIS OF THIS INSTRUMENT FOR PUBLIC POLICIES OF TREATMENT}

\footnotetext{
${ }^{1}$ Arquiteta e Urbanista, Universidade Federal da Bahia, Professora, patimfarias@gmail.com

${ }^{2}$ Arquiteta e Urbanista, Universidade Federal da Bahia, Professora, anyivo@gmail.com

${ }^{3}$ Graduanda do Curso Bacharelado Interdisciplinar, Universidade Federal da Bahia. bagsoares@gmail.com

${ }^{4}$ Graduando do Curso Bacharelado Interdisciplinar, Universidade Federal da Bahia. laerciosouza36@hotmail.com
} 

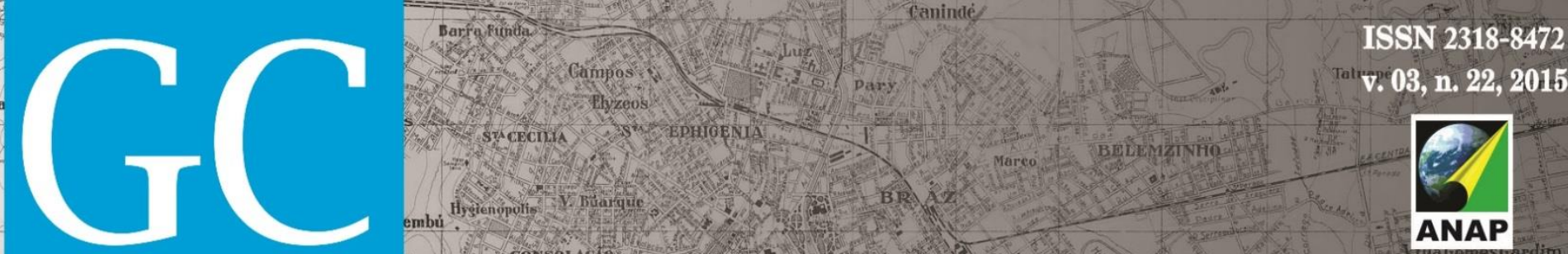

Revista Nacional de

Gerenciamento de Cidades

\begin{abstract}
In Brazil, the aging process has received much attention in recent literature. Analysis and discussion of instruments that facilitate the autonomy and independence of the elderly are needed. This study aims to evaluate the elderly's access to information necessary for them to exercise their rights stipulated by public policy. First, a literature search was conducted on guidebooks for the elderly to determine the amount of information available regarding public policy. Using a systematic methodology, the quantity and quality of guidebooks for the elderly in Brazil were analyzed, from public institutions. The results presented have confirmed some initial observations of the researchers. The guidebooks have different forms of presentation and language that should be treated with appropriate criteria. The contents of guidebooks for the elderly discuss the Elderly Statute and local needs with language and formats often inadequate for what is being proposed. Another point noted was the lack of guidelines regarding living space. From the observations and perceptions of the surveyed guidebooks, it was concluded that these instruments can be made more efficient and meaningful to the life of the elderly.
\end{abstract}

KEYWORD: idoso; políticas públicas; cartilhas

\title{
FOLLETOS PARA LOS ANCIANOS? UN ANÁLISIS DE ESTE INSTRUMENTO DE POLÍTICAS PÚBLICAS DE TRATAMIENTO
}

\section{RESUMEN}

En Brasil, el proceso de envejecimiento ha recibido mucha atención en la literatura reciente. Se necesitan análisis y discusión de los instrumentos que facilitan la autonomía e independencia de las personas mayores. Este estudio tiene como objetivo evaluar el acceso de las personas mayores a la información necesaria para el ejercicio de sus derechos estipulados en la política pública. En primer lugar, se realizó una búsqueda bibliográfica en las guías para los ancianos, para determinar la cantidad de información disponible en relación con las políticas públicas. Utilizando una metodología sistemática, la cantidad y calidad de guías para las personas mayores en Brasil se analizaron, de públicas instituciones. Los resultados presentados han confirmado algunas observaciones iniciales de los investigadores. Las guías tienen diferentes formas de presentación y lenguaje que debe ser tratado con criterios adecuados. El contenido de las guías para los ancianos discuten el Estatuto del Anciano y necesidades locales con idiomas y formatos a menudo insuficiente para lo que se propone. Otro punto señalado fue la falta de directrices relativas a espacio de vida. A partir de las observaciones y percepciones de las guías turísticas encuestadas, se concluyó que estos instrumentos se pueden hacer más eficiente y significativo para la vida de las personas mayores.

PALABRA CLAVE: Ios ancianos; política pública; guía

\section{INTRODUÇÃO}

Estima-se que o ser humano "esteja programado" para viver entre 110 e 120 anos. Seu ciclo vital atinge maturidade biológica, o ápice da vitalidade, por volta dos 25, 30 anos. Dos 25 até os 40 o indivíduo pode ser considerado um adulto inicial; até 65 anos, adulto médio ou de meia idade, dos 65 até 75 anos, adulto tardio na velhice 
Revista Nacional de

Gerenciamento de Cidades

precoce, e desta idade em diante, vem a chamada velhice tardia (Palácios, 2004). Segundo o Relatório Nacional Brasileiro sobre o Envelhecimento da População Brasileira divulgado pelo IBGE, cresce a proporção de idosos que vivem sozinhos. Em 2030, a proporção de idosos será de $30 \%$ da população do país e o número de jovens está diminuindo em relação à proporção de idosos (IBGE, 2008). A longevidade tem sido, portanto, discutida como uma realidade brasileira, entretanto, é preciso assegurar anos a mais de vida com dignidade e saúde. Este rápido processo de envelhecimento populacional do país sinaliza sérios desafios para as políticas públicas, pois o idoso tem ocupado um papel cada vez mais significativo na sociedade moderna.

A progressão da idade pode representar a possibilidade de fortalecimento e ampliação dessa população de idosos no espaço público de forma ativa, contribuindo para um desenvolvimento sustentável dessa geração no espaço urbano. O nível de independência revelado na mobilidade e nas atividades físicas diárias, por exemplo, podem permitir o alcance e manutenção de um envelhecimento bem sucedido. Satisfazer as necessidades das gerações atuais, sem comprometer a capacidade das gerações futuras satisfazerem suas próprias necessidades é uma tarefa a ser enfrentada pelo Estado e pela sociedade que requer novos e urgentes instrumentais de governança. Demandas diferenciadas e específicas de cada etapa do processo de envelhecimento exigirão a adoção de práticas sustentáveis que potencializem o envelhecimento ativo e saudável.

No âmbito jurídico, tem sido ampliada a publicação de legislação específica que trate de políticas públicas voltadas para a necessidade do idoso. A promulgação da Constituição Brasileira de 1988 possibilitou a participação da sociedade na elaboração de políticas públicas e a criação de novas leis que deram alcance do olhar para o idoso pela sociedade, valorizando este segmento específico da população. A Política Nacional do Idoso, Lei 8.842/1994 (regulamentada pelo Decreto $n^{\circ} 1.948 / 96$ ) apresenta diretrizes que ampliam e aprofundam questões não abordadas na Constituição como priorização do idoso em diversos setores da 
Revista Nacional de

Gerenciamento de Cidades

sociedade, criação de programas que garantam os direitos da pessoa idosa e dos conselhos estadual e municipal. A partir destes marcos regulatório, outras leis foram incorporadas ao caso específico da Pessoa Idosa, como a LOAS (Lei Orgânica de Assistência Social), especialmente a seção que trata sobre o BPC (Benefício de Prestação Continuada). Por outro lado, têm sido publicadas ações do Estado que caminham no sentido contrário desta corrente de construção de uma longevidade ativa. A extinção do abono de permanência recentemente apresentada ao Congresso pela Presidência da República como Proposta de Emenda à Constituição 139/2015 é um exemplo deste equívoco. O abono referido atua como um incentivo ao servidor que continua a exercer suas atividades laborais, tendo completado os requisitos para requerer aposentadoria. Desta forma, a extinção do abono de permanência estimula o requerimento de aposentadorias por uma população de idosos que estavam, até então, na ativa por receber esta gratificação compensatória.

O Estatuto do Idoso é promulgado, por meio da Lei 10.741/2003, com uma incorporação da Politica Nacional de Saúde da Pessoa Idosa por meio da Portaria no 2.528/2006 e questões específicas que foram surgindo desde a sua elaboração em 1994. A mais nova publicação, entretanto, é o Compromisso Nacional para Envelhecimento Ativo consolidado pelo Decreto Presidencial oㅜ 8.114/2013. Este decreto permite garantir a comunicação entre os órgãos e as entidades públicas e monitorar as ações de promoção do envelhecimento ativo que proporcione qualidade de vida, fortalecendo as políticas e programas de promoção de uma sociedade inclusiva.

Estimativas divulgadas pela Organização Mundial da Saúde apontam que a população mundial de idosos em 2025 poderá chegar a 1,2 bilhões de pessoas. 0 envelhecimento populacional no Brasil provocou a transformação da velhice em um problema social, dessa forma o aumento quantitativo das pessoas idosas tem sido a principal preocupação dos governos diante do aumento das demandas e das pressões que acarreta o envelhecimento populacional. 
A partir desta perspectiva em construir uma sociedade humana sustentável, a inclusão do idoso na participação do processo de elaboração e formulação das Políticas Públicas que ampliem os benefícios, serviços, programas e projetos, depende de um conhecimento prévio da legislação e dos direitos por parte do idoso. A cartilha é um instrumento de aproximação do idoso com as garantias de direitos, utilizando uma linguagem mais clara e acessível. A publicação da cartilha é uma iniciativa de Estado que facilita e complementa projetos de governança.

O presente trabalho é resultado de uma atividade curricular complementar de natureza extensionista e de pesquisa, no âmbito da graduação do curso de Arquitetura e Urbanismo da UFBA, ministrada a partir do segundo semestre de 2014, intitulada Habitação Saudável, Moradia Digna e Direito a Cidade.

\section{OBJETIVO}

O objetivo deste artigo é analisar a frequência e a qualidade do acesso de políticas públicas pelos os idosos a partir das cartilhas sobre o Estatuto do Idoso publicadas pelas instituições federais, estaduais e municipais, observando, também, a existência ou não, nestas cartilhas, da abordagem de questões arquitetônicas no ambiente de morar do idoso. Estas cartilhas proporcionam o acesso à legislação por meio da apresentação de um formato mais didático e de uma linguagem lúdica. $A$ escolha da análise deve-se ao fato de que é através destas cartilhas que a sociedade civil e, incluindo, os idosos, têm acesso ao que o texto da lei transmite com uma linguagem menos jurídica.

\section{METODOLOGIA}

Este trabalho foi elaborado a partir de pesquisa documental e de campo, desenvolvida por meio do levantamento das cartilhas publicadas após o Estatuto do Idoso promulgado em $1^{\circ}$ de outubro de 2013 até o ano de 2015 e contato com as 


\section{Revista Nacional de}

ouvidorias dos órgãos públicos. Foram consideradas publicações, em todo o território nacional, relacionadas às três esferas: municipal, estadual e federal. Outro critério utilizado foi a seleção de cartilhas que informassem o conteúdo do Estatuto do Idoso de forma integral ou de forma parcial.

A pesquisa documental recorre a fontes mais diversificadas e dispersas, sem tratamento analítico, tais como: tabelas estatísticas, jornais, revistas, relatórios, documentos oficiais, cartas, filmes, fotografias, pinturas, tapeçarias, relatórios de empresas, vídeos de programas de televisão, etc. (FONSECA, 2002, p. 32).

Algumas cartilhas pesquisadas, entretanto, não continham a informação de ano de publicação. Só foi possível saber que estes documentos eram registrados a partir de 2003, por meio do reconhecimento do conteúdo do Estatuto do Idoso no corpo do texto.

A pesquisa de campo caracteriza-se pelas investigações em que, além da pesquisa bibliográfica e/ou documental, se realiza coleta de dados junto a pessoas, com o recurso de diferentes tipos de pesquisa (pesquisa ex-post-facto, pesquisaação, pesquisa participante, etc.) (FONSECA, 2002). .

A pesquisa foi realizada por meio de endereços eletrônicos de órgãos públicos. Como já foi mencionado, anteriormente, além das buscas em meio digital, foi realizado um contato com as ouvidorias. Os e-mails, em sua maioria, não foram respondidos e, quando houve algum retorno, as respostas não foram positivas quanto à existência de material jurídico informativo publicado em formato de cartilha.

A fim de contemplar os objetivos a que se propõe este trabalho, a pesquisa documental e de campo abordou uma análise geral sobre cartilhas através da elaboração de um quadro onde foram classificados por esferas públicas (municipal, estadual e federal) e levantados os principais pontos críticos do documento, inclusive a questão da existência ou não de orientações técnicas de arquitetura para o ambiente de morar do idoso. 


\section{RESULTADOS E DISCUSSÃO}

A Cartilha do Estatuto do Idoso é um instrumento informativo facilitado que apresenta conteúdos jurídicos em formato didático por serem, muitas vezes, complexos de serem compreendidos pela sociedade civil.

A partir das pesquisas realizadas foi possível reunir 26 cartilhas no total, sendo 5 publicações da esfera federal, 16 publicações da esfera estadual e 5 publicações da esfera municipal (Gráfico 1).

\section{Gráfico 1 - Números de Cartilhas Pesquisadas por Esferas Públicas}

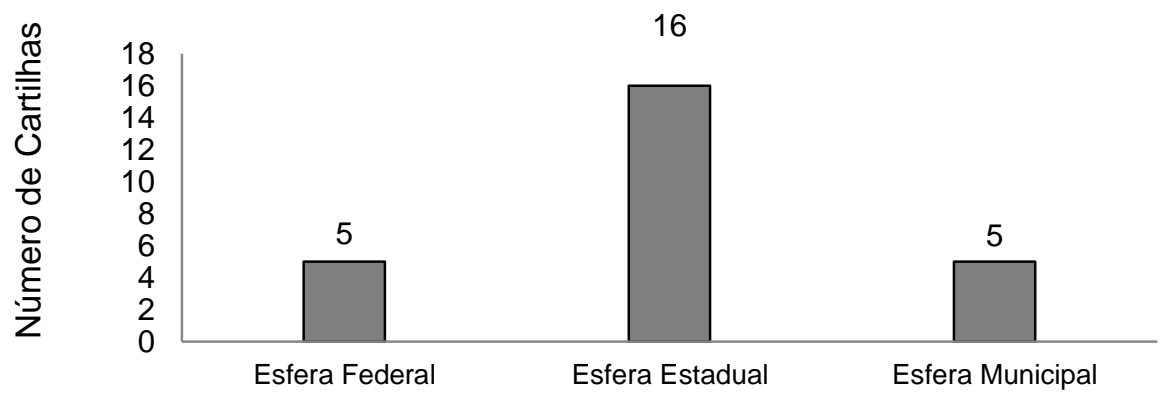

Vale ressaltar que durante a pesquisa, as cartilhas não eram encontradas disponíveis facilmente e esperava-se que a cartilha fosse um instrumento mais utilizado no setor público.

Os e-mails enviados para as ouvidorias, em sua maioria, não foram respondidos e, quando houve algum retorno, as respostas não foram positivas quanto à existência de material jurídico informativo publicado em formato de cartilha. A esfera estadual foi a que mais apresentou cartilhas publicadas e disponíveis online.

As cartilhas apresentaram estruturas de texto diferentes. Algumas continham textos organizados por perguntas e respostas e outras apresentavam textos corridos com uma estratégia de linguagem mais comum ao leitor. 
A partir desta etapa, foi possível organizar as cartilhas por órgãos públicos e verificou-se que os Ministérios Públicos Estaduais e as Defensorias Públicas se destacaram em maior número de publicações, totalizando em 10 dentre as 26 cartilhas pesquisadas. Dentre estes estavam: Ministério Público do Estado da Bahia, Ministério Público do Estado do Ceará, Ministério Público do Distrito Federal, Ministério Público do Estado de Rondônia, Ministério Público de Pernambuco, Ministério Público do Estado de São Paulo, Defensoria Pública do Estado de São Paulo, Defensoria Pública do Estado do Ceará, Defensoria Pública do Distrito Federal e Defensoria Pública do Estado do Maranhão)

Os 15 documentos apresentados no gráfico como "outros" constituíram uma variedade de parcerias (Gráfico 2).

\section{Gráfico 2 - Números de cartilhas por Órgãos Públicos}

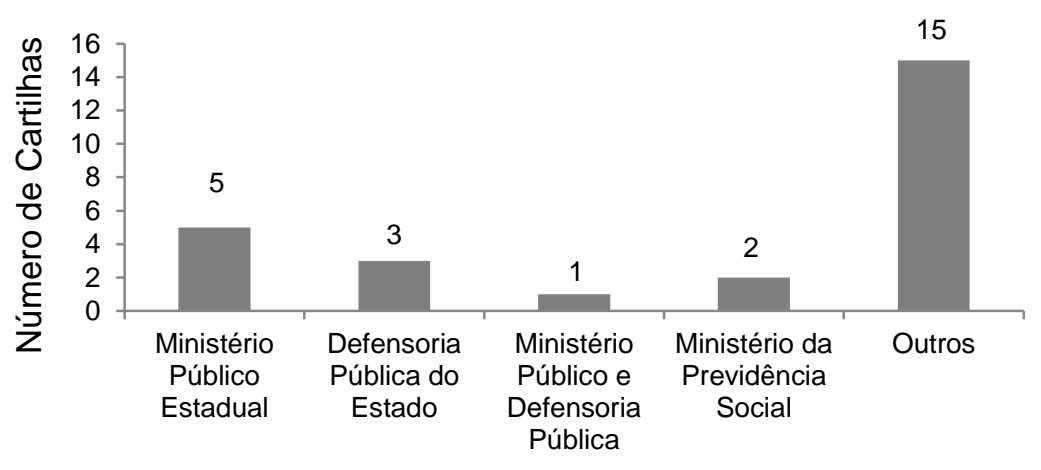

Os dados quantitativos mostram que ao longo de onze anos de publicação do Estatuto do Idoso, a região Sudeste foi a que mais produziu e divulgou informações sobre os direitos da Pessoa Idosa. Se verificarmos ainda a publicação de cartilhas por Estado, veremos que o Estado de São Paulo se destaca dos demais e o Distrito Federal apresenta a segunda produção maior, considerando que as produções do Distrito Federal estão voltadas para divulgação do Governo Federal. (Gráfico 3). 


\section{Gráfico 3 - Número de Cartilhas por Estado}

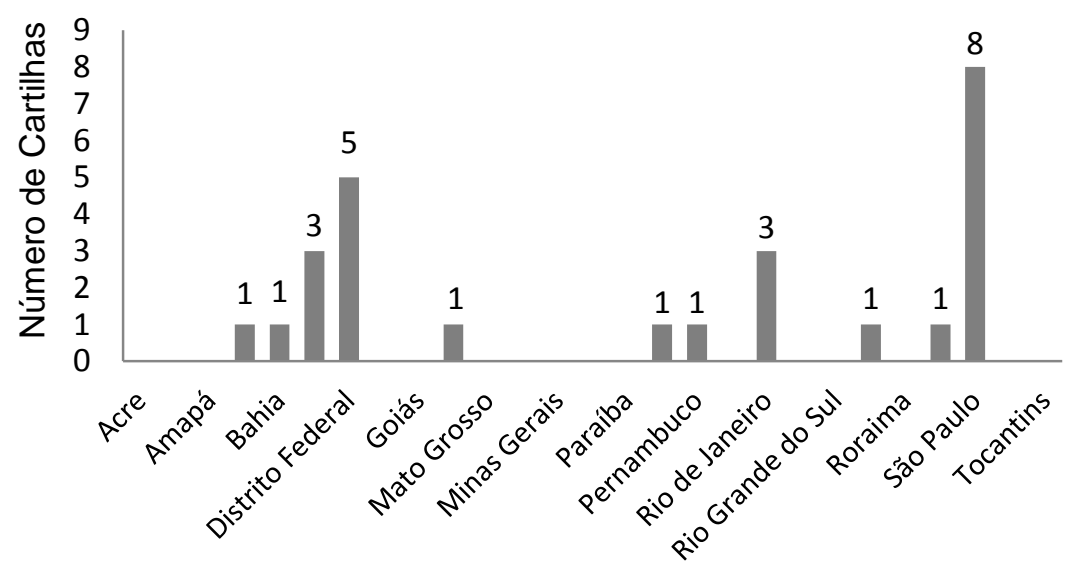

O Estado do Ceará se destaca em relação à qualidade e quantidade de cartilhas publicadas, pois é o único estado em que o Ministério Público Estadual (MPE) publicou duas edições de um mesmo material, na primeira edição intitulada "Idoso Cidadão - Combate a Violência contra a Pessoa Idosa" (MPECE, sd), o MPE do Ceará se preocupou em abordar o tema da violência contra os idosos. $\mathrm{Na}$ segunda edição, intitulada "Idoso Cidadão - Autonomia e Direitos do Idoso" (MPECE, sd), o MPE abrange o Estatuto do Idoso de maneira mais ampla, esclarecendo em sua apresentação a diferença entre as duas publicações, sendo a primeira sobre a violência contra a pessoa idosa por causa do contexto de urgência e necessidade de discussão do tema abordado e a segunda sobre o Estatuto em todos os seus artigos.

Os conteúdos apresentados nas cartilhas refletem diferenças regionais. Determinadas temáticas ou questões são abordadas de maneira mais aparente em determinadas publicações, como por exemplo a campanha contra a violência contra a pessoa idosa, informação que recebeu uma publicação inteira na publicação do Ministério Público do Estado do Ceará ( MPECE, sd). Outras cartilhas, como as publicações do Ministério Público de Rondônia Cartilha do Idoso (MPERO, sd) e da Defensoria Pública do Ceará (ADPEC, 2013), reservaram espaço para falar sobre vacinação. 
Existem, também, pontos convergentes na confecção das cartilhas, considerando que as publicações são frutos de um documento em comum (O Estatuto do Idoso). A questão do transporte público, entretanto, parece ser, ao mesmo tempo, demanda local e nacional. Todas as cartilhas que tratam sobre 0 Estatuto de forma mais generalizada, tratam do assunto, saindo do âmbito nacional para se concentrar na legislação local.

Dentro da proposta da pesquisa, um dos pontos analisados foi o item sobre orientações do espaço do idoso, considerando que no artigo 37 do Estatuto do Idoso este usuário de terceira idade tem direito à moradia digna. Na maioria das cartilhas, o item é simplificado. Uma cartilha, intitulada "Cartilha do Idoso - Acessibilidade e Atendimento Prioritário à Pessoa Idosa" (UERJ e UNATI, 2010) apresenta a discussão sobre o direito à acessibilidade do idoso. Apesar de explicitar esta questão, a cartilha envolve a questão da acessibilidade a pessoas com deficiência, agrupando os idosos e deficientes numa mesma discussão de necessidades e demandas. Esta unificação se torna inadequada, considerando que as necessidades dos idosos são diferentes das necessidades da pessoa com deficiência. Estes dois grupos requerem tratamentos de necessidades complexas e particulares.

A publicação, entretanto, traz pequenas orientações para a organização do ambiente em que o idoso reside. Desta forma, verificamos que dos 26 artigos, 23 (representando $73 \%$ do total pesquisado) trazem a abordagem sobre o direito à habitação presente no Estatuto do Idoso.

O artigo $38^{\circ}$ do Estatuto do Idoso prevê: "eliminação de barreiras arquitetônicas e urbanísticas, para garantia da acessibilidade do idoso" (Estatuto do Idoso, 2003), entretanto este conteúdo não aparece de forma frequente e nem detalhada nas cartilhas. É possível consultar o Quadro 1 e verificar que 23 cartilhas abordam o direito à habitação presente no Estatuto do Idoso e dessas 23, apenas 3 cartilhas ampliam o conteúdo e trazem recomendações para utilização do espaço, entretanto, de forma superficial ainda. As 3 cartilhas restantes não abordam o direito à habitação. 


\section{Revista Nacional de}

Gerenciamento de Cidades

Vale ressaltar, entretanto, que a diversidade cultural e o processo de desenvolvimento urbano de uma cidade tem particularidades específicas, especialmente, a identidade local da terceira idade soteropolitana.

\section{Quadro 1 - Cartilhas que abordam o Direito à Habitação presente no Estatuto do Idoso}

\begin{tabular}{|c|c|c|}
\hline Titulo e Referências & Esfera Pública & observação \\
\hline Vida longa e cidadania: conheça o Estatuto do Idoso. (CÂMARA DOS DEPUTADOS, 2004) & Federal & Cita todo art. Do Estatuto \\
\hline Idoso - Cidadão Brasileiro: informações sobre serviços e direitos. (MINISTÉRIO DA PREVIDÊNCIA SOCIAL, 2008) & Federal & Cita os programas de habitação \\
\hline Amigo do Idoso: justiça social para assegurar os direitos da melhor idade. (ANADEP, 2009) & Federal & Cita apenas os $3 \%$ \\
\hline Cidadão Idoso - Parceiro de uma Vida Inteira. (MINISTÉRIO DA PREVIDÉNCIA SOCIAL, sd) & Federal & Não cita \\
\hline Cartilha do Idoso. (ASSOCIAÇÃO BRASILEIRA DE DEFESA DO CONSUMIDOR, 2013) & Federal & Cita e traz exemplos de programas habitacionais no RJ e SP \\
\hline Em defesa do cidadão idoso. (DPEM, sd) & Estadual & Cita todo art. Do Estatuto \\
\hline Cartilha do Idoso: $\mathrm{O}$ que você precisa saber. (DF, 2013) & Estadual & Cita o estatuto e traz outras legislações como a Politica Nacional do Idoso \\
\hline Cartilha do Idoso. (MPERO, sd) & Estadual & Cita apenas os $3 \%$ \\
\hline Cartilha do Idoso. (OAB/SP, 2013) & Estadual & Cita, traz recomendações e discute com uma arquiteta consultora \\
\hline Acessibilidade e Atendimento Prioritário à Pessoa Idosa. (UERJ e UNATI, 2010) & Estadual & Cita e traz recomendações \\
\hline Preto C, Braga CES. Cartilha do Idoso: Guia Prático e Normas Correlatas $2^{8}$ Edição.(Preto C, Braga CES, 2009) & Estadual & Cita todo art. Do Estatuto \\
\hline Cartilha do Idoso. (MPESP, 2007) & Estadual & Cita sobre a salubridade das casas de repouso, mas direciona para a ANVISA \\
\hline Direitos do Idoso (SindiCT, 2009). & Estadual & Cita e traz outras legislações municipais e estaduais \\
\hline Estatuto do Idoso: Vamos descomplicar? (DPESP, 2010) & Estadual & Cita e discute sobre salubridade \\
\hline Guia da Pessoa Idosa $2^{2}$ Edição: Dicas e Direitos. (SEDH, 2010) & Estadual & Cita apenas os $3 \%$ \\
\hline Guia prático de direitos da pessoa idosa. (UNESP, 2013) & Estadual & Cita e fala sobre salubridade \\
\hline Idoso Cidadão $2^{8}$ Ediçẫo: Autonomia e Direitos do Idoso. (MPECE, sd) & Estadual & Cita e traz recomendações \\
\hline Idosos: Nós defendemos. (ADPEC, 2013) & Estadual & Cita apenas os $3 \%$ \\
\hline Idoso Cidadão: Combate à Violência contra a pessoa Idosa.( MPECE, sd) & Estadual & Não cita \\
\hline Idoso no exercicio da cidadania. (MPPE, 2012) & Estadual & Não cita \\
\hline Voz da Experiência. Conselho do idoso. Implantação e fortalecimento. (MPEBA, 2013) & Estadual & Cita apenas os $3 \%$ \\
\hline Os direitos do idoso. (PREFEITURA DE SÄO PAULO, sd) & Municipal & Cita todo art. Do Estatuto \\
\hline A Terceira Idade e seus Direitos. (Mota MLS, 2005) & Municipal & Cita e traz outras legislações municipais e/ou estaduais \\
\hline Os direitos da pessoa idosa. (PREFEITURA DE CURITIBA, sd) & Municipal & Cita todo art. Do Estatuto \\
\hline Conselho Municipal do Idoso: criação e atuação. (MPESC, 2014) & Municipal & Cita todo art. Do Estatuto \\
\hline Manual do Idoso (OAB/SP, 2007) & Municipal & Cita e traz outras legislações municipais e/ou estaduais \\
\hline
\end{tabular}

É possível perceber que num país tão diversificado como o Brasil, as demandas recorrentes em cartilhas produzidas na região nordeste apresentam problemáticas a serem trabalhadas diferentes das cartilhas produzidas no sul do país.

Outro ponto observado na análise das cartilhas foi a linguagem utilizada. Muitas das cartilhas pesquisadas revelaram uma linguagem direcionada ao cuidador e não ao idoso. Isso reflete uma postura equivocada dos órgãos de governança que precisam não somente incorporar 0 idoso nas políticas públicas, mas nos instrumentos voltados para este público social. Outra questão é a adoção de linguagem ou representação infantilizada destas cartilhas. A apresentação em quadrinhos pode contribuir para facilitar o entendimento das questões de direitos do Estatuto, entretanto, esta forma de publicação deve ser feita de forma cuidadosa a fim de evitar o constrangimento e o não reconhecimento por parte do idoso ao receber a cartilha. 


\section{CONCLUSÃO}

A riqueza de informações que foi possível extrair e resgatar das cartilhas possibilitou ampliar o entendimento destes objetos de estudo cuja compreensão necessita de contextualização com o local e as demandas reais. A partir destas análises podemos perceber que as cartilhas são instrumentos que aproximam a sociedade civil do conhecimento jurídico e devem ser elaboradas, considerando aspectos locais e o público alvo. O reconhecimento do direito à vida, à dignidade e à longevidade deve ser objeto da agenda oficial dos governos. Questões voltadas para o espaço de morar do idoso precisam ser mais trabalhadas em formato de cartilha com orientações de medidas preventivas de arquitetura. Observando que o Estatuto do Idoso traz a questão da moradia digna como um item pontual, caberia desenvolver um trabalho de orientação mais detalhado sobre o espaço de morar pois o idoso possui especificidades nas suas necessidades que deveriam ser mais discutidas e implementadas nas políticas públicas. As ações de governança precisam estar mais amparadas de orientações de especialistas na área para evitar publicações equivocadas e inadequadas para o público alvo em questão. Considerando uma sociedade voltada para o conceito de sustentabilidade humana, é preciso desenvolver critérios mais cuidadosos no tratamento de instrumentos públicos de qualidade.

\section{REFERÊNCIAS}

Brasil. Leis etc. Estatuto do ldoso, lei $n^{\circ} 10.741$, de $1^{\circ}$ de outubro de 2003. 1a․ ed. Brasília: Ministério da Saúde; 2003

Fonseca JJS. Metodologia da pesquisa científica. 2002; Apostila.

Gerhardt TE, Silveira DT. Métodos de Pesquisa. Porto Alegre: Editora UFRGS; 2009.

Instituto Brasileiro de Geografia e Estatística (IBGE). Projeção da População do Brasil por Sexo e Idade 1980-2050. Rio de Janeiro: Instituto Brasileiro de Geografia e Estatística, 2010. 


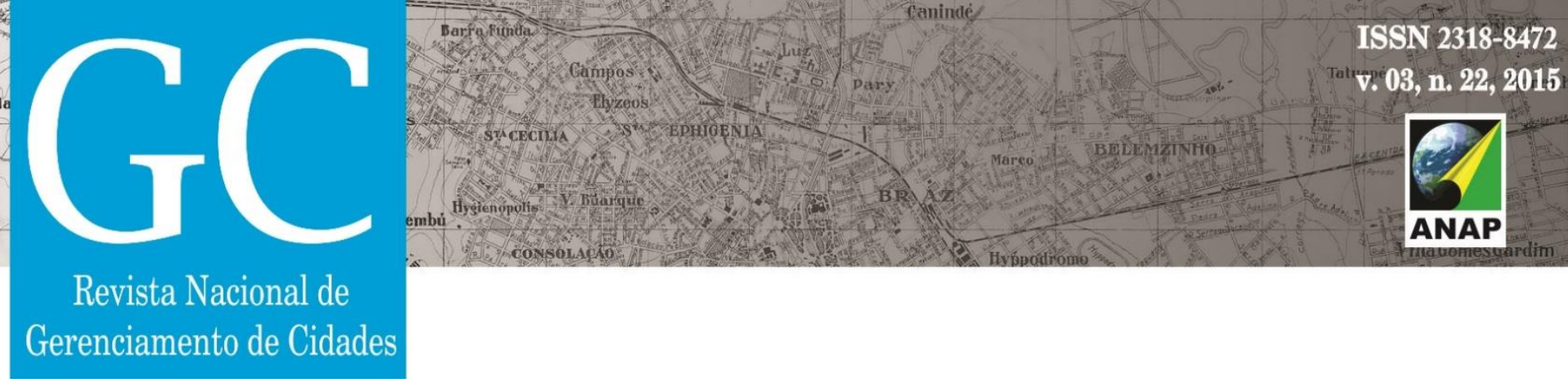

Ordem dos Advogados do Brasil Seção de São Paulo (BR). Cartilha do Idoso. São Paulo: Comissão dos Direitos dos Advogados Idosos, 2013. Disponível em:

http://www.portalterceiraidade.org.br/pdf_files/cartilha_idoso_2013_v2.pdf

Universidade Estadual Paulista (UNESP), Pró-Reitoria de Extensão Universitária. Guia prático de direitos da pessoa idosa. São Paulo: UNESP, PROEX, 2013. Disponível em:

http://unesp.br/portal\#!/terceira-idade/

Defensoria Pública do Estado Maranhão (DPEM), Centro Integrado de Apoio e Prevenção à Violência contra a Pessoa Idosa. Em defesa do cidadão idoso. São Luís: Defensoria Publica do Estado do Maranhão. Disponível em:

http://www.dpe.ma.gov.br/dpema/documentos/16fa833f90d15ea0511c307db23b6e14.pdf

Ministério Público do Estado de Pernambuco (MPPE), Procuradoria Geral de Justiça. Idoso no exercício da cidadania. Recife: Ministério Público de Pernambuco, 2012. Disponível em: http://siteantigo.mppe.mp.br/uploads/y4R0nm4XTttFjOh91CSmBA/Cartilha_do_Idoso_SITE.pdf

Universidade Estadual do Rio de Janeiro (UERJ), Universidade Aberta da Terceira Idade (UNATI). Acessibilidade e Atendimento Prioritário à Pessoa Idosa. Rio de Janeiro: Universidade Estadual do Rio de Janeiro, 2010. Disponível em: http://www.unatiuerj.com.br/cartilha1.pdf

Secretaria Especial dos Direitos Humanos (BR), Secretaria de Estado da Casa Civil do Rio de Janeiro, Centro Integrado de Atenção e Prevenção à Violência Contra a Pessoa Idosa. Guia da Pessoa Idosa 2a Edição: Dicas e Direitos. Rio de Janeiro: Secretária Especial dos Direitos Humanos, 2010. Disponível em: http://www.ortoplan.com/uploads/Cartilhaldoso_3aEdicao.pdf

Prefeitura de Curitiba (BR), Fundação de Ação Social. Os direitos da pessoa idosa. Curitiba: Prefeitura de Curitiba. Disponível em: www.fas.curitiba.pr.gov.br/baixarMultimidia. aspx?idf=397

Ordem dos Advogados do Brasil Seção de São Paulo (BR), 56ª subseção da Ordem dos Advogados do Brasil, Prefeitura Municipal de Osasco. Manual do Idoso: Ordem dos Advogados do Brasil Seção de São Paulo, 2007. Disponível em: http://www.oabsp.org.br/comissoes2010/advogados-

idosos/cartilhas/manual_idoso.pdf

Palácios, J. (2004). Mudança e Desenvolvimento Durante a Idade Adulta e a Velhice. Em C. Coll, J. Palacios, \& A. Marchesi. Desenvolvimento Psicológico e Educação Psicologia Evolutiva Vol.12a .Ed. Porto Alegre: Artmed.

Preto C, Braga CES. Cartilha do Idoso: Guia Prático e Normas Correlatas 2ª Edição. Manaus, 2009. Disponível em: http://josenorberto.com.br/Cartilha_idoso_Antt.pdf

Sindicato Nacional dos Servidores Públicos Federais na Área de Ciência e Tecnologia do Setor Aeroespacial (SindiCT). Direitos do Idoso. São Paulo: SindiCT, 2009. Disponível em: http://www.sindct.org.br/index.php?q=node/1677

Ministério da Previdência Social; Instituto Nacional da Seguridade Social (BR), Centro de Formação e Aperfeiçoamento do INSS/ Programa de Educação Previdenciária. Cidadão Idoso - Parceiro de uma Vida Inteira. Brasília: Ministério da Previdência Social. Disponível em:

http://www.previdencia.gov.br/arquivos/office/1_121017-104915-755.pdf 
Revista Nacional de Gerenciamento de Cidades

Associação Brasileira de Defesa do Consumidor (BR). Cartilha do Idoso. Rio de Janeiro: Proteste, 2013. Disponível em: http://www.proteste.org.br/familia/nc/noticia/cartilha-do-idoso-baixe-agora

Mota MLS. A Terceira Idade e seus Direitos. São Paulo, 2005. Disponível em:

http://www.incor.usp.br/sites/incor2013/docs/ouvidoria/cartilha_idosos.pdf

Ministério Público de Santa Catarina (MPESC), Centro de Apoio Operacional dos Direitos Humanos e Terceiro Setor. Conselho Municipal do Idoso: criação e atuação. Florianópolis: Ministério Público de Santa Catarina, 2014. Disponível em:

http://documentos.mpsc.mp.br/portal/manager/resourcesDB.aspx?path=378

Tribunal de Justiça do Distrito Federal e Territórios (DF), Central Judicial do Idoso. Cartilha do Idoso: O que você precisa saber. Brasília: Tribunal de Justiça do Distrito Federal e Territórios, 2013.

Disponível em: http://www.tjdft.jus.br/institucional/2a-vice-presidencia/nupecon/central-judicial-doidoso/copy3_of_Cartilhadoldoso_COMALTERAES_25092013.pdf/view

Ministério Público do Estado de São Paulo (MPESP), Defensoria Pública do Estado de São Paulo, Centro de Apoio operacional Promotorias de Justiças Cíveis do Idoso e das Pessoas com Deficiência, Grupo de Atuação Especial de Proteção ao Idoso. Cartilha do Idoso. São Paulo: Ministério Público do Estado de São Paulo / Defensoria Pública do Estado de São Paulo, 2007. Disponível em: https://www.anadep.org.br/wtksite/cartilhaidoso.pdf 